\title{
Yeni Kırılgan Beşli Ülkelerinde Gelir Eşitsizliğinin Ekonomik Büyümeye Etkileri $^{1}$
}

The Effects of Income Inquality on Economic Growth in New Fragile Five

\section{Countries}

Ahmet KAMACI ${ }^{2}$

Article Info

Article History:

Date Submitted: 05.08.2019

Date Accepted: 27.08.2019

Jel Classification

O40, O50, D30

Keywords:

GINI coefficient,

Economic growth,

New fragile five countries,

Panel data analysis
Abstract

Brazil, India, Indonesia, Turkey and South Africa referred as the "fragile five" by Morgan Stanley, 1 August 2013. After this describing, in November 2017, Standard\&Poor's suggest that the Turkey, Argentina, Qatar, Egypt and Pakistan are the new "fragile five" and this countries needed foreign capital flows to eliminate the current account deficit. In these countries, there are problems such as high inflation, large current account deficits, coerced capital flow expectations, external security deficit and unstable growth. The New Fragile Five countries identified by Standard \& Poor's are included in the study.

Lorenz curve or Gini coefficient obtained from Lorenz curve is used to measure income inequality. Gini coefficient is between 0 and 1 and the income inequality decreases as the coefficient approaches 0 , and the income inequality increases as it approaches 1. Although the origin of the relationship between income inequality and economic growth dates back to Smith, it is synonymous with Kuznets' inverse U hypothesis. According to this hypothesis, income inequality initially increased and it will decrease after a certain point.

In this study, the Fragile Five new countries (Turkey, Argentina, Qatar, Egypt and Pakistan), effect of income inequality on economic growth for the 1996-2016 period were tested with panel data analysis. In this context cross-sectional dependence was tested in the series and it was found that the series were stationary to the different degree. Then the direction and coefficients of the relationship were determined with ARDL model. According to the results of this study, 1 unit increase in GINI coefficient decreases economic growth by $-2,644$ units in the long run term.

\footnotetext{
${ }^{1}$ Bu çalışma, 25-26 Nisan 2019 tarihlerinde Ankara'da düzenlenen "Fiscaoeconomia International Congress on Social Sciences" kongresinde özet olarak sunulan "Yeni Kırılgan Beşli Ülkelerinde Gelir Eşitsizliğinin Ekonomik Büyümeye Etkileri” adlı sunumun genişletilmiş ve tamamlanmış halidir.

${ }^{2}$ Dr. Öğr. Üyesi, Bartın Üniversitesi İiBF İktisat Bölümü
} 


\section{Özet}

1 Ağustos 2013'de Morgan Stanley tarafından Kırılgan Beşli olarak anılan (Brezilya, Hindistan, Endonezya, Türkiye ve Güney Afrika) ve daha sonra Kasım 2017'de Standard\&Poor's farklı bir Kırılgan Beşli tanımlamasıyla (Türkiye, Arjantin, Katar, Mısır ve Pakistan) değiştirilen Kırılgan Beşli ülkeleri cari açığı gidermek için yabancı sermaye akımlarına ihtiyaç duymaktadır. Bu ülkelerde yüksek enflasyon, büyük cari hesap açıkları, zorlayıcı sermaye akımı beklentileri, dış güvenlik açığı, istikrarsız büyüme gibi sorunlar mevcuttur. Çalışmada Standard\&Poor's tarafindan belirlenen Yeni Kırılgan Beşli ülkelerine yer verilmiştir.

Gelir eşitsizliğini ölçmek için Lorenz eğrisi ya da Lorenz eğrisinden elde edilen Gini katsayısı kullanılmaktadır. Gini katsayısı 0 ile 1 arasındadır. Katsayı 0’a yaklaştıkça gelir eşitsizliği azalmakta, 1'e yaklaştıkça gelir eşitsizliği artmaktadır. Gelir eşitsizliği ile ekonomik büyüme ilişkisinin kökeni Smith’e kadar dayansa da Kuznets'in “ters U hipotezi” ile özdeşleşmiştir. Bu hipoteze göre, gelir eşitsizliği başlangıçta artarken; belli bir noktadan sonra gelir eşitsizliği azalacaktır.

Bu çalışmada, Yeni Kırılgan Beşli ülkelerinde (Türkiye, Arjantin, Katar, Mısır ve Pakistan) 1996-2016 dönemleri için gelir eşitsizliğinin ekonomik büyümeye etkileri panel veri analiziyle test edilmiştir. Bu kapsamda, serilerde yatay kesit bağımlılığı sınanmış ve serilerin farklı derecede durağan olduğu tespit edilmiştir. Daha sonra ARDL modeliyle ilişkinin yönü ve katsayıları belirlenmiştir. Bu çalışmanın sonucuna göre, GINI katsayısındaki 1 birimlik artış uzun dönemde ekonomik büyümeyi -2,644 birim azaltmaktadır.

\section{Giriş}

Dünyadaki gelir eşitsizliği Sanayi Devriminden sonra ortaya çıksa da özellikle 1980’den sonra ciddi artış göstermiştir. Az gelişmiş ve gelişmekte olan ülkeler mali liberalizasyona hazır olmadan dışa açılma sürecine girmiş ve zayıf ekonomilerini büyük güçlerin etkisine maruz bırakmıştır. Mali liberalizasyon ekonomik büyümeye olumlu etki yaparken, diğer yandan gelir eşitsizliği artmıştır. Öyle ki; gelişmiş ülkelerden daha yüksek büyüme oranlarına sahip olan gelişmekte olan ülkeler, yaşam standardını yükseltememiş ve gelir adaletsizliğinde büyük artışlar görülmüştür (Danışoğlu, 2004:216-217). Gelir adaletsizliği genelde Gini katsayısı ile ölçülmektedir. Gini katsayısı, gelir eşitsizliğini ölçen temel göstergelerden biridir ve gelirin toplumlar arasında ne denli adil dağıtılıp dağıtılmadığını gösterir. Gini katsayısı, 0 ile 1 
arasındadır. Katsayı 1'e yaklaşırsa gelir eşitsizliği artarken; 0’a yaklaşırsa gelir eşitsizliği azalmaktadır (Yanar ve Şahbaz, 2013:61).

2013'den itibaren gündeme gelen Kırılgan Beşli kavramı, ülkelerde değişmeler yaşansa da halen devam etmektedir. Kırılganlık kavramından kastedilen, yabancı sermaye akımlarına aşırı ihtiyaç duyulmasıdır. Bu ülkelerde, yüksek cari açık, yüksek enflasyon, istikrarsız büyüme ve zorlayıcı yabancı sermaye akımları gibi birçok sorun bulunmaktadır. Nitekim Kasım 2017'de Standard\&Poor's'un Yeni Kırılgan Beşli tanımlamasında Türkiye, Arjantin, Katar, Mısır ve Pakistan gibi ülkeler vardır. Çalışmaya konu olan sınıflandırma da bu ülkeleri kapsamaktadır.

Bu çalışmanın temel amacı, Yeni Kırılgan beşli ülkelerinde ${ }^{3}$ 1996-2016 dönemine ait yıllık veriler yardımıyla gelir eşitsizliğinin ekonomik büyümeye etkisini incelemektir. $\mathrm{Bu}$ kapsamda, öncelikle konuyla alakalı teorik çerçeve çizilmiş ve konuyla ilgili literatür taramasına yer verilmiştir. Daha sonra Yeni Kırılgan Beşli kavramı ele alınarak ülkelere ait göstergelere yer verilmiştir. 1996-2016 dönemine ait Yeni Kırılgan Beşli ülkelerinde gelir eşitsizliğinin ekonomik büyümeye etkisini ele alan bu çalışmada, yatay kesit bağımlılığı test edilmiş ve seriler farklı dereceden durağan oldukları için ARDL modeli kurularak kısa ve uzun dönemli ilişkinin varlı̆g 1 tespit edilmiştir.

\section{Kavramsal Çerçeve ve Literatür Taraması}

Büyüme ile gelir eşitsizliği ilişkisini açıklayan birçok teori vardır. Bu teoriler 3 eksende ele alınabilir. İlk teori, gelir eşitsizliği ile ekonomik büyüme arasında pozitif ilişki kuran klasik yaklaşımdır. Smith tarafından geliştirilen, Keynes, Lewis ve Kaldor'un da savunduğu bu teoriye göre, tasarruflar arttıkça sermaye birikimi artmakta ve böylece ekonomik büyüme de artmaktadır. 2.teori ise gelir eşitsizliği ile ekonomik büyüme arasında anlamsal bir ilişki kurmayan Neoklasik yaklaşımdır. Solow ve Swan'ın savunduğu bu teoriye göre, eşitsizliğin büyüme üzerinde bir etkisi yoktur. Son teori ise gelir eşitsizliğinin farklı kanallar aracılığıyla büyümeyi negatif etkilediğini ileri süren Modern yaklaşımdır (Topuz ve Yıldırım, 2017:60). $\mathrm{Bu}$ teorileri rağmen gelir eşitsizliği ile ekonomik büyüme arasındaki ilişki Kuznets hipotezi olarak bilinmektedir.

\footnotetext{
${ }^{3}$ Türkiye, Arjantin, Katar, Mısır ve Pakistan.
} 
Gelir eşitsizliği ile ekonomik büyüme ilişkisi 1955 'de Simon Kuznets'in makalesinde ileri sürülmüş ve 1963 'deki makalesinde de yapılan analizle teorik altyapısı oluşturulmuştur. Kuznets'e göre, ekonomik büyümenin ilk evrelerinde gelir eşitsizliği artarken, daha sonra eşitsizlik azalacaktır (Kuznets, 1955). Gelir eşitsizliği ile gelir düzeyi arasındaki bu ilişki “Ters U Hipotezi” olarak adlandırılmaktadır.

Şekil 1: Kuznets'in Ters U Eğrisi

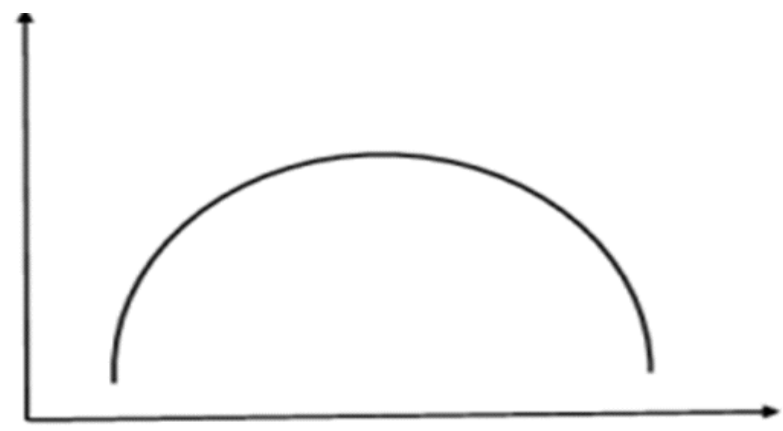

Kaynak: Weil, 2016:389.

Şekil 1'de dikey eksende gelir eşitsizliği, yatay eksende ise kişi başı gelir yer almaktadır. Buna göre, sermaye başlangıçta kıt faktör olduğundan dönüm noktasına kadar eşitsizlik artacaktır. Ancak dönüm noktasından sonra sermaye bollaşacağından eşitsizlik azalacaktır. Böylece eşitsizliğin ilerleyen dönemlerde azalacağını ileri sürmektedir.

Gelir eşitsizliği ile ekonomik büyüme arasındaki ilişkileri ele alan çalışmalar, Kuznets'in çalışmasını temel almaktadır. Ancak birçok çalışmada farklı yöntemler, veriler ya da zamanlar ele alındığı için farklı sonuçlara ulaşılmıştır. Gelir eşitsizliği ile ekonomik büyüme arasındaki ilişkiyi ele alan çalışmalar genelde panel veri analiziyle test edilmiştir ve iki değişken arasında farklı sonuçlar elde edilmiştir. Panel veri analizi kullanılarak elde edilen bu çalışmalardan Persson ve Tabellini (1994), 9 ülkede çoğu kesitli olarak 1830-1985 dönemleri için gelir eşitsizliğgi ile ekonomik büyüme arasındaki ilişkiyi incelemiştir. Çalışmanın sonucuna göre, gelir eşitsizliği arttıkça ekonomik büyüme azalmaktadır. Perotti (1996) ise, 1960-1985 dönemi için farklı ülke grupları için bu ilişkiyi incelemiş ve gelir eşitsizliğinin sonraki dönemler için ekonomik büyümeyi pozitif yönde etkilediğini göstermiştir. Barro (2000) ise "Inequality and Growth in a Panel of Countries" adlı çalışmasında Gini katsayısı ve ekonomik büyümeyi ayrı ayrı bağımsız değişken olarak çalışmaya dâhil edilmiştir. 1960-1995 dönemini ele alan bu çalışma, dışa açıklık ile gelir eşitsizliği üzerine pozitif ilişkiler verirken; gelir ile Gini arasındaki ilişkinin ise ülkelerin gelişmişlik düzeylerine göre farklılık gösterdiğini işaret etmiştir. Buna 
göre, gelir eşitsizliği bazı ülkelerde ekonomik büyümeyi negatif etkilerken; bazı ülkelerde ekonomik büyüme pozitif etkilenmektedir. Özdemir vd. (2011) ise çalışmalarında, 15 geçiş ekonomisinde 1992-2007 dönemleri arasında bu ilişkiyi incelemiş ve gelir eşitsizliği ile kişi başı gelir arasında pozitif bir ilişki tespit etmiştir. Topuz ve Dağdemir (2016) çalışmalarında, 94 ülkede 1995-2011 dönemleri arasında gelir eşitsizliği ile ekonomik büyüme arasındaki ilişkiyi incelemiştir. Çalışmanın sonucuna göre, düşük, alt-orta ve üst-orta gelirli ülkelerde ekonomik büyüme sayesinde gelir eşitsizliği artarken; yüksek gelirli ülkelerde ekonomik büyüme gelir eşitsizliğini azaltmaktadır. Çakmak ve Tosun (2017) ise, 25 ülkede 2002-2013 dönemleri için bu ilişkiyi incelemiş ve kişi başı gelir arttıkça gelir eşitsizliğinin önce azaldığını, belli bir noktadan sonra ise arttığını belirtmiştir. Topuz ve Yıldırım (2017) ise, 154 ülkede 19802014 dönemleri için bu ilişkiyi incelemiş ve farklı sonuçlar bulmuştur. Bu çalışmanın sonucuna göre, düşük ve alt-orta gelirli ülkelerde gelir eşitsizliği ekonomik büyümeyi arttırırken; yüksek gelirli ülkelerde gelir eşitsizliği ekonomik büyümeyi azaltmaktadır. Şahin (2018) ise, 15 gelişmiş ülkede 1995-2014 dönemleri için finansal gelişme ile gelir eşitsizliği arasındaki ilişkiyi incelemiştir. Çalışmanın sonucuna göre, ekonomik büyüme ile gelir eşitsizliği arasında herhangi bir nedensellik mevcut değildir. Vo vd. (2019) ise çalışmalarında, 86'sı orta gelirli 158 ülkede 1960-2014 dönemleri için gelir eşitsizliği ile ekonomik büyüme arasındaki ilişkiyi incelemiştir. GMM yönteminin kullanıldığı bu çalışmanın sonucuna göre, ekonomik büyümeden gelir eşitsizliğine doğru bir nedensellik mevcuttur. Özellikle orta gelirli ülkelerde gelir eşitsizliği ekonomik büyümeye olumsuz etki yapmaktadır.

Gelir eşitsizliği ile ekonomik büyüme arasındaki ilişkiyi Türkiye için ele alan çalışmalar da mevcuttur ve bu çalışmalarda da farklı sonuçlar elde edilmiştir. Bu çalışmalardan Dişbudak ve Süslü (2009), Türkiye’de 1963-1998 dönemi için gelir dağılımı ile ekonomik büyüme ilişkisini incelemiştir. ARDL modelinin kullanıldığı bu çalışmanın sonucuna göre, gelirdeki artışlar gelir dağılımında düzeltmeye işaret etse de; belli bir gelir düzeyinden sonra gelir dağılımının bozulduğu görülmektedir. Ak ve Altıntaş (2016) ise, 1986-2012 dönemleri için bu ilişkiyi incelemiş ve kişi başı gelirin ilk dönemler gelir eşitsizliğini azalttığını, daha sonraki dönemlerde ise eşitsizlik azalttığını ifade etmiştir. Diğer bir ifadeyle gelir dağılımındaki eşitsizlik kişi başı gelirde önce düzeltme, daha sonra ise bozulma eğilimindedir. Peçe vd. (2016) ise, iki değişken arasındaki bu ilişkiyi 1977-2013 dönemleri için incelemiş ve Gini katsayısı azalırken kişi başı reel GSYİH arttığını tespit etmiştir. Destek vd. (2017) ise çalışmalarında, Türkiye'de 1977-2013 dönemleri için gelir dağılımı ile finansal gelişme arasındaki ilişkiyi 
incelemiştir. ARDL modelinin kullanıldığı bu çalışmanın sonucuna göre, reel GSYİH'nın artması gelir dağılımı adaletini pozitif yönde etkilemektedir. Akalin vd. (2018) ise çalışmalarında, Türkiye'de 1984-2011 dönemleri arasında gelir eşitsizliği ile ekonomik büyüme arasındaki ilişkiyi incelemiştir. Kuadratik ve kübik model kullanarak ilişkinin yönü tahmin edilmiştir. Kuadratik model kullanılarak elde edilen tahminci sonuçlarına göre kişi başına gelir ile Gini katsayısı arasında ters U şeklinde bir ilişki varken; kübik model kullanılarak elde edilen tahminci sonuçlarında kişi başına gelir ile Gini katsayısı arasında ters N şeklinde bir ilişki vardır.

Gelir eşitsizliği ile ekonomik büyüme arasındaki ilişkiyi farklı ülkeler için de ele alan çalışmalar mevcuttur. Bu çalışmalardan, Wahiba ve El-Weriemmi (2014) çalışmalarında, Tunus'ta 1984-2011 dönemleri için gelir eşitsizliği ile ekonomik büyüme arasındaki ilişkiyi incelemiştir. Çalışmanın sonucuna göre, gelir eşitsizliği ile ekonomik büyüme arasında negatif bir ilişki mevcuttur. Tabosa vd. (2016) ise çalışmalarında, Brezilya'da 1981-2013 dönemleri için bu ilişkiyi incelemiş ve gelir eşitsizliğindeki bir azalmanın ekonomik büyümeyi arttırdığ sonucuna ulaşmıştır.

\section{Yeni Kırılgan Beşli Kavramı ve Ülkelere Ait Göstergeler}

FED'in 22 Mayıs 2013'de tahvil alımlarını azaltacağı açıklamasından sonra yüksek ve artan cari açıklarını gidermek için yabancı sermaye akımlarına ihtiyaç duyan ülkeler sıkıntıya girmiştir. 1 Ağustos 2013'de Morgan Stanley tarafından hazırlanan raporda bu ülkeler Kırılgan Beşli (Fragile Five) olarak kabul edilmiştir. Bu ülkeler; BIITS (Brezilya, Hindistan, Endonezya, Türkiye ve Güney Afrika) olarak adlandırılmaktadır. Kırılgan beşli ülkelerinde yüksek enflasyon, büyük cari hesap açıkları, zorlayıcı sermaye akımı beklentileri, dış güvenlik açı̆̆ı, yükselen piyasalardaki zayıf ve istikrarsız büyüme gibi birçok problem vardır (Stanley, 2013:1,16). Morgan Stanley 2016'nın sonlarında göstergeleri iyileşen Brezilya ve Hindistan'1 gruptan çıkarırken, Meksika ve Kolombiya'yı gruba dâhil etti. Bu tanımlamadan sonra, yeni kırılgan beşli Endonezya, Türkiye, Güney Afrika, Kolombiya ve Meksika olmuştur (Eğilmez, 2017).

Kasım 2017'de Standard\&Poor's farklı bir Kırılgan Beşli sınıflandırması yaptı. Eski kırılgan beşli ülkelerinden Türkiye hariç tüm ülkeler çıktı. Yeni Kırılgan Beşli ülkeleri Türkiye, Arjantin, Katar, Mısır ve Pakistan'dır. Standard\&Poor's bu ülkeler arasında da en kırılgan 
ülkenin Türkiye olduğunu açıklamıştır (Palacıoğlu, 2018:6). Çalışmaya konu olan sınıflandırma da bu ülkeleri kapsamaktadır.

Tablo 1'de Türkiye ekonomisine ait göstergeler yer almaktadır.

Tablo 1: Türkiye Ekonomisine Ait Göstergeler

\begin{tabular}{|l|l|l|l|l|l|l|}
\hline $\begin{array}{l}\text { Çeşitli } \\
\text { Göstergeler }\end{array}$ & 2013 & 2014 & 2015 & 2016 & 2017 & 2018 \\
\hline Büyüme (\%) & 8,5 & 5,2 & 6,1 & 3,2 & 7,4 & 2,6 \\
\hline İşsizlik (\%) & 9 & 9,9 & 10,3 & 10,9 & 10,9 & 11,6 \\
\hline Enflasyon (\%) & 7,4 & 8,2 & 8,8 & 8,5 & 11,92 & 20,3 \\
\hline $\begin{array}{l}\text { Gösterge Faiz } \\
\text { Yıllık } \\
\text { Ortalama (\%) }\end{array}$ & 10,1 & 8 & 11,2 & 10,6 & 14 & 24 \\
\hline $\begin{array}{l}\text { Bütçe Dengesi/ } \\
\text { GSYİH (\%) }\end{array}$ & -1 & $-1,1$ & -1 & $-1,1$ & $-1,6$ & $-1,9$ \\
\hline $\begin{array}{l}\text { Diş Borç Stoku } \\
\text { /GSYİH (\%) }\end{array}$ & 41 & 43 & 46,3 & 46,8 & 53,3 & 53,4 \\
\hline $\begin{array}{l}\text { Cari denge/ } \\
\text { GSYİH (\%) }\end{array}$ & $-6,8$ & -5 & $-3,8$ & $-3,8$ & $-5,5$ & $-3,5$ \\
\hline
\end{tabular}

Kaynak: Eğilmez:2017, TCMB, BUMKO, databank.worldbank.org

Tablo 1'e göre, Türkiye ekonomisinde çoğu gösterge iyi değildir. Ekonomik büyüme rakamları son yıllarda düşüş göstermekte ve işsizlik oranları artmaktadır. Enflasyon ve faiz oranları 2000'li yıllardaki gibi sürekli artmaktadır. Cari açık son yıllarda azalsa da bütçe açığı ve dış borç stokunda artışlar gözlemlenmektedir. Bütün bu göstergeler Türkiye ekonomisinin kırılgan bir yapıda olduğunu göstermektedir.

$\mathrm{Bu}$ çalışmada, gelir eşitsizliği ile ekonomik büyüme arasındaki ilişki panel veri analiziyle test edilmiştir. Gelir eşitsizliğini ölçmek için Lorenz eğrisi ya da Lorenz eğrisinden elde edilen Gini katsayısı kullanılır. Gini katsayısı 0 ile 1 arasındadır. 1'e yaklaştıkça eşitsizlik artar ve 0'a yaklaştıkça eşitsizlik azalır (Kamacı vd., 2019:42).

Şekil 2’de Yeni kırılgan beşli ülkelerine ait Gini katsayısı verilmiştir. 
Şekil 2: Yeni Kırılgan Beşli Ülkelerinde Gini Katsayısı (2016)

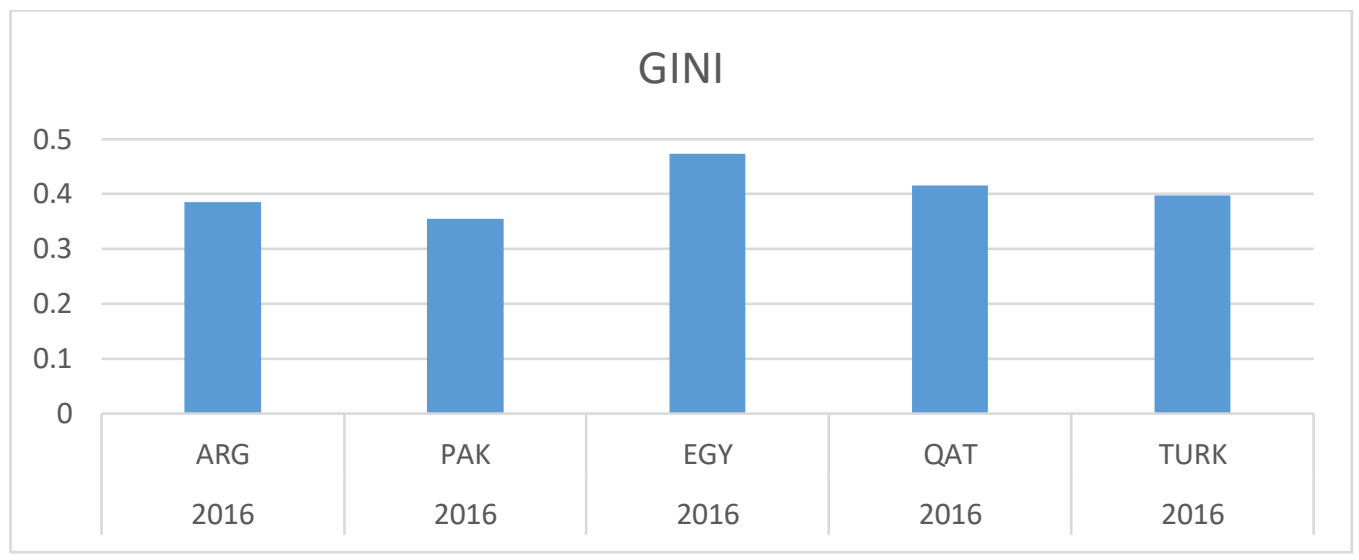

Kaynak: https://dataverse.harvard.edu/dataset

Şekil 2'ye göre, 2016'da Yeni Kırılgan Beşli ülkelerinde Gini katsayısı en çok olan ülke 0,474 ile Mısır'dır. Diğer bir deyişle, yeni kırılgan beşli ülkelerinde gelir eşitsizliğinin en çok olduğu ülke Mısır'dır. 2016 itibariyle eşitsizliğin en az olduğu ülke ise 0,355 ile Pakistan'dır.

Türkiye genelinde ele alındığında ise, gelir eşitsizliğinin azaldığı, ancak hâlâ yüksek olduğu görülmektedir. Şekil 3'de Türkiye’ye ait Gini katsayısı göstergeleri verilmiştir.

Şekil 3: Türkiye'de Gini Katsayısı (1996-2016)

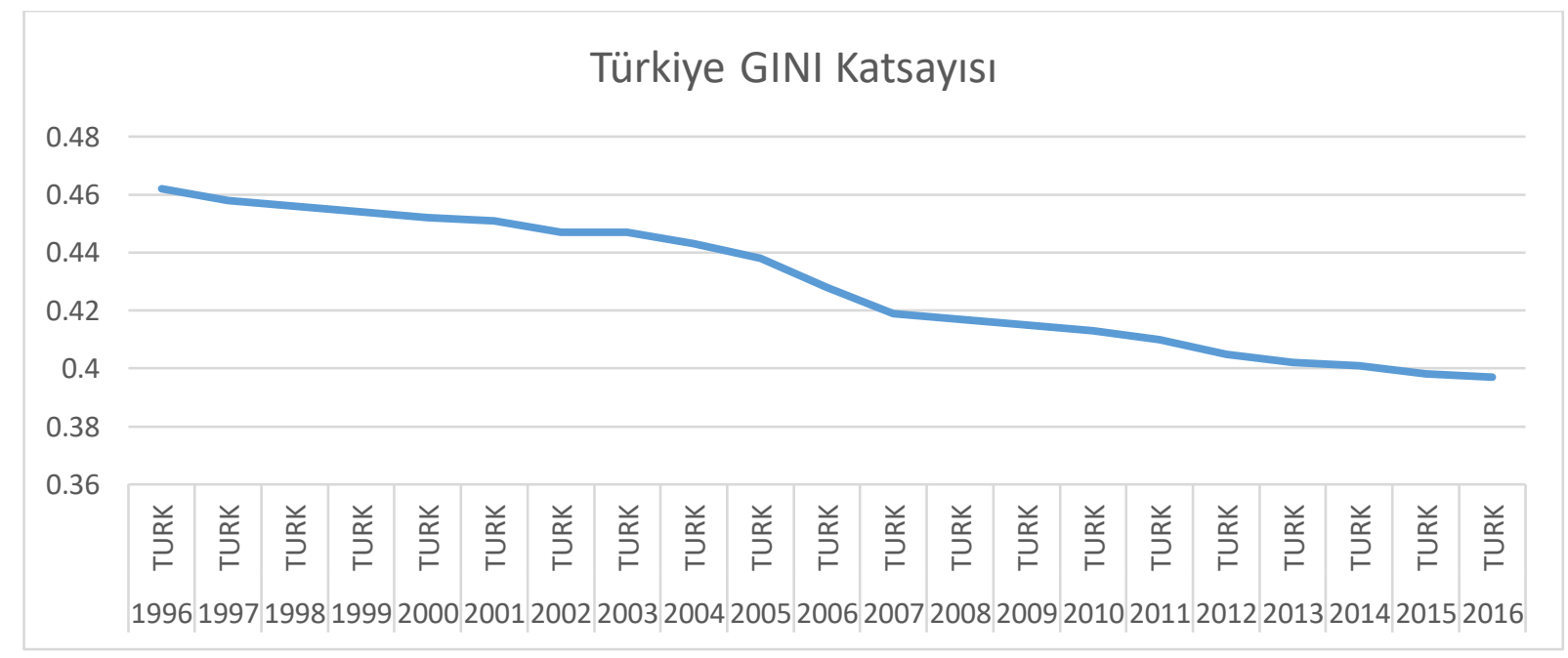

Kaynak: https://dataverse.harvard.edu/dataset

Şekil 3'e göre, Türkiye'de 1996-2010 arası gelir eşitsizliğinin azaldığı görülmektedir. Eşitsizliğin en çok olduğu yıl 1996'dır ve Gini katsayısı 0,462'dir. Daha sonra eşitsizlik azalmakta ve 2016 'da 0,397 ile en düşük değeri almaktadır. 


\section{Ekonometrik Yöntem ve Bulguların Değerlendirilmesi}

\subsection{Veri Seti ve Model}

Bu çalışmada Yeni Kırılgan Beşli ülkelerinde 1996-2016 yılları arasında gelir eşitsizliği ile ekonomik büyüme arasındaki ilişki panel veri analiziyle test edilmiştir. $\mathrm{Bu}$ çalışmada bağımsız değişken gelir eşitsizliğini gösteren GINI katsayısıdır ve analizde "LOGGINI" olarak yer almaktadır. Bağımlı değişken ise ekonomik büyümedir ve analizde "LOGGROW" olarak yer almaktadır. Çalışmada 1 no'lu model tahmin edilecektir:

$$
\text { LOGGROW }_{\text {it }}=\alpha_{0}+\alpha_{1} \text { LOGGINI }_{\text {it }}+\varepsilon_{\text {it }}
$$

Serilerin logaritmaları alınmış ve kurulan model neticesinde, serilerde yatay kesit bağımlılığının tespiti için $\mathrm{CD}_{\mathrm{LM}}$ testine başvurulmuştur. Farklı derecede durağan çıkan serilere de ARDL modeli kurulup iki değişken arasındaki kısa ve uzun dönemli ilişki belirlenmiştir.

\subsection{Ampirik Sonuçlar}

Yatay kesit bağımlılı̆̆ı, analizlerdeki sonuçların sapmalı ve tutarsızlı̆̆ını önlemek amacıyla hangi panel birim kök testlerinin uygulanacağına karar vermektedir (Koçbulut ve Altıntaş, 2016:152). Seriler yatay kesit bağımlılığı varsa ikinci nesil panel birim kök testleri uygulanır. Tablo 2'de gelir eşitsizliği ile ekonomik büyüme için yatay kesit bağımlılığ sonuçları verilmiştir.

Tablo 2:Yatay Kesit Bağımlılı̆g $\left(\mathrm{CD}_{\mathrm{LM}}\right)$ Testi

\begin{tabular}{|l|l|c|c|}
\hline \multicolumn{1}{|c|}{ Değişken } & \multicolumn{1}{|c|}{ CD Test } & \multicolumn{1}{|c|}{$\begin{array}{c}\text { Test } \\
\text { İstatistiği }\end{array}$} & Prob. \\
\hline LOGGINI & $\begin{array}{l}\text { CD } \\
\text { LM1 (Breusch- } \\
\text { Pagan LM) }\end{array}$ & 81.52108 & 0.0000 \\
\hline LOGGINI & $\begin{array}{l}\text { CD } \\
\text { scaled LM) (Pesaran }\end{array}$ & 15.99260 & 0.0000 \\
\hline LOGGINI & $\begin{array}{l}\text { Bias Corrected } \\
\text { Scaled LM }\end{array}$ & 15.86760 & 0.0000 \\
\hline LOGGINI & Pesaran CD & 3.473248 & 0.0005 \\
\hline LOGGROW & $\begin{array}{l}\text { CD } \\
\text { LM1 (Breusch- }\end{array}$ & 13.90140 & 0.1775 \\
& Pagan LM) & & \\
\hline
\end{tabular}




\begin{tabular}{|l|l|c|c|}
\hline LOGGROW & $\begin{array}{l}\text { CD } \\
\text { LM2 (Pesaran } \\
\text { scaled LM) }\end{array}$ & 0.872349 & 0.3830 \\
\hline LOGGROW & $\begin{array}{l}\text { Bias Corrected } \\
\text { Scaled LM }\end{array}$ & 0.74379 & 0.4548 \\
\hline LOGGROW & Pesaran CD & 2.778690 & 0.0055 \\
\hline
\end{tabular}

Tablo 2'ye göre, LOGGINI değişkeninin olasılık değeri 0.05'den küçük olduğu için yatay kesit bağımlılı̆g vardır. Ancak LOGGROW değişkeninin olasılık değeri 0.05 'den büyük olduğu için yatay kesit bağımlılı̆̆1 yoktur. Bu yüzden LOGGINI değişkeni için ikinci nesil panel birim kök testi, LOGGROW serisi için ise birinci nesil panel birim kök testi kullanılmıştır. Tablo 3'de LOGGINI değişkeni için CADF birim kök testi sonuçları verilmiştir.

Tablo 3: CADF Birim Kök Testi Sonuçları

\begin{tabular}{|l|l|r|}
\hline Değişkenler & IPS W-stat. & Olasılık değ. \\
\hline LOGGINI & -0.79352 & 0.2137 \\
\hline$\Delta$ LOGGINI & -2.44572 & 0.0072 \\
\hline
\end{tabular}

Tablo 3'e göre, LOGGINI serisi birim kök içermektedir ve 1.fark1 alınarak durağan hale getirilmiştir.

Tablo 4'de ise LOGGROW değişkenine ait birinci nesil panel birim kök testi sonuçları verilmiştir.

Tablo 4: LOGGROW Değişkeni İçin Birim Kök Testi Sonuçları

\begin{tabular}{|l|l|l|}
\hline Metot & İstatistik & Olasıllk Değeri \\
\hline LLC & -3.30587 & 0.0005 \\
\hline IPS & -2.77418 & 0.0028 \\
\hline ADF & 27.0732 & 0.0025 \\
\hline PP & 29.3368 & 0.0011 \\
\hline Breitung & -1.88415 & 0.0298 \\
\hline
\end{tabular}

Tablo 4'e göre, tüm testler için olasılık değeri 0.05 'den küçük olduğu için ekonomik büyüme verisi seviyesinde durağandır. Ekonomik büyüme serisi seviyesinde durağanken, GINI 
katsayısı 1.farkta durağandır. Seriler farklı dereceden durağan oldukları için ARDL modeli kullanılmıştır. Tablo 5'de ARDL modeli sonuçları verilmiştir.

Tablo 5: ARDL Kısa ve Uzun Dönem Sonuçları

\begin{tabular}{|l|l|l|l|}
\hline \multicolumn{4}{|c|}{ Bağımlı Değişken: LOGGROW } \\
\hline Değişken(ler) & \multicolumn{1}{|c|}{ Katsayı } & t-istat. & Olasılık Değ. \\
\hline \multicolumn{2}{|c|}{ UZUN DÖNEM } & -229.6548 & 0.0000 \\
\hline LOGGINI & -2.6444489 & -2.192594 & 0.0315 \\
\hline \multicolumn{2}{|c|}{ KISA DÖNEM } & 0.197348 & 0.8441 \\
\hline CointEq (-1) & -0.479099 & & \\
\hline d(LOGGINI) & 2.349621 &
\end{tabular}

Tablo 5'deki katsayılar kısa ve uzun dönem katsayılarını ve kısa dönemde sistemin dengeye geldiğini göstermektedir. Sonuçlara göre, gelir eşitsizliği ile ekonomik büyüme arasında uzun dönem katsayıları anlamlıyken, kısa dönem katsayısı anlamsızdır. Bu sonuçlara göre, GINI katsayısındaki 1 birimlik artış uzun dönemde ekonomik büyümeyi -2,644 birim azaltmaktadır. Analiz sonuçlarına göre, gelir eşitsizliği ile ekonomik büyüme arasındaki uzun dönemli negatif ilişki literatüre uygundur.

\section{Sonuç}

Gelir dağılımı, bir ülkede üretilen milli gelirin bireyler ve toplumlar arasında dağılımını göstermektedir. Üretim faktörleri ne derece adil dağıtılırsa, gelir dağılımı o kadar adildir. Özellikle az gelişmiş ve gelişmekte olan ülkelerde gelir dağılımında ciddi eşitsizlikler vardır. Bu eşitsizlik birçok yöntemle ölçülse de genelde Gini katsayısı kullanılmaktadır. Gini katsayısı, 0 ile 1 arasındadır. Katsayı 1'e yaklaşırsa gelir dağ̊lımı adaletsizliği artarken; 0'a yaklaşırsa gelir dağılımı adaletsizliği azalmaktadır.

FED'in 22 Mayıs 2013'de tahvil alımlarını azaltacağı yönündeki açıklamasından sonra yabancı sermaye akımlarına aşırı ihtiyaç duyan ülkelerin para birimlerinde ciddi değer kaybı görülmüştür. Morgan Stanley Ağustos 2013'de bu ülkeleri Kırılgan Beşli (Fragile Five) olarak adlandırmıştır. Bu ülkeler; BIITS (Brezilya, Hindistan, Endonezya, Türkiye ve Güney Afrika) olarak adlandırılmaktadır. Bu ülkeler, yüksek cari açık, yüksek enflasyon, sermaye akımına aşırı ihtiyaç, yüksek dış borç ve istikrarsız büyüme gibi birçok problemle karşı karşıyadır. 2016'da Morgan Stanley cari açığı ve kırılganlığı azalan Brezilya ve Hindistan'ı gruptan 
çıkarırken, Meksika ve Kolombiya'yı gruba dâhil etti. Nitekim Kasım 2017'de Standard\&Poor's farklı bir Kırılgan Beşli sınıflandırması yaptı. Türkiye haricinde tüm ülkeler gruptan çıkarken Arjantin, Katar, Mısır ve Pakistan gruba dâhil edildi. Bu çalışmada da yeni kırılgan beşli ülkeleri kullanılmıştır.

Bu çalışmada, Yeni Kırılgan Beşli ülkelerinde 1996-2016 dönemleri için gelir eşitsizliği ile ekonomik büyüme arasındaki ilişki panel veri analiziyle test edilmiştir. Bu çalışmada bağımsız değişken 0 ile 1 arasında bir değer alan ve endeks değeri 0'a yaklaştıkça eşitsizliğin azaldığını gösteren Gini katsayısıdır. Bağımlı değişken ise ekonomik büyümedir. Çalışmada serilerde yatay kesit bağımlılı̆̆ının tespiti için CDLM testi uygulanmış ve Gini katsayısının yatay kesit bağımlılığı içerdiği ama ekonomik büyüme değişkeninin yatay kesit bağımlılığ içermediği tespit edilmiştir. Bu yüzden Gini katsayısına yatay kesit bağımlılığı bulunduğundan dolayı ikinci nesil panel birim kök testlerinden CIPS panel birim kök testi; ekonomik büyüme değişkenine de birinci nesil panel birim kök testlerinde LLC, IPS, ADF, PP ve Breitung panel birim kök testleri uygulanmıştır. Değişkenlerden ekonomik büyüme serisi seviyesinde durağanken; gelir eşitsizliği değişkeni 1.farkı alınarak durağan hale gelmiştir. Bu durumda farklı mertebelerde durağanlığa izin veren Panel ARDL modeliyle katsayılar tahmin edilmiştir. $\mathrm{Bu}$ çalışmanın sonucuna göre, gelir eşitsizliği ile ekonomik büyüme arasında uzun dönem katsayıları anlamlıyken, kısa dönem katsayısı anlamsızdır. GINI katsayısındaki 1 birimlik artış uzun dönemde ekonomik büyümeyi -2,644 birim azaltmaktadır. Bulunan bu negatif ilişki literatüre uygundur.

\section{Kaynakça}

Ak, M.Z. ve Altıntaş, N. (2016). Kuznets'in Ters U Eğrisi Bağlamında Türkiye'de Gelir Eşitsizliği ve Ekonomik Büyüme İlişkisi: 1986-2012. Maliye Araştırmaları Dergisi, 2(3): 93-102.

Akalin, G., Özbek, R.İ. ve Çifçi, İ. (2018). Türkiye'de Gelir Dağılımı ve Ekonomik Büyüme Arasındaki İlişki: ARDL Sınır Testi Yaklaşımı. Kastamonu Üniversitesi İİB Dergisi, 20(4): 59-76.

Barro, R. J. (2000). Inequality and Growth in a Panel of Countries, Journal of Economic Growth, 5: 5-32.

Çakmak, A.İ. ve Tosun, B. (2017). Ekonomik Büyüme-Gelir Dağılımı İlişkisi: Kuznets Hipotezinin Seçilmiş Ülkeler Üzerine Araştırılması. Kosbed, 2017, 33: 33 - 44. 
Danışoğlu A. Ç. (2004). Küreselleşmenin Gelir Eşitsizliği ve Yoksulluk Üzerindeki Etkileri. İstanbul Ticaret Üniversitesi Dergisi,3(6):215-239.

Destek, M.A., Okumuş, İ. ve Manga, M. (2017). Türkiye'de Finansal Gelişim ve Gelir Dağglımı İlişkisi: Finansal Kuznets Eğrisi. Doğuş Üniversitesi Dergisi, 18 (2) 2017, 153-165.

Dişbudak, C. ve Süslü, B. (2009). Kalkınma ve Bireysel Gelir Dağılımı: Kuznets Hipotezi Türkiye İçin Geçerli mi. Akdeniz İ.İ.B.F. Dergisi (18), 146-166.

Eğilmez, M. (2017). Türkiye Ekonomisi Niçin Kırılgan Beşli Arasında. Kendime Yazılar, 26 Kasım 2017.

Kamac1, A., Ceyhan, M.S. ve Peçe, M.A. (2019). The Analysis of the Effect of Real Interests on Income Distribution with ARDL Model Approach. Afro Eurasian Studies, 8(1): 3954.

Koçbulut, Ö. ve Altıntaş, H. (2016). İkiz Açıklar ve Feldstein-Horioka Hipotezi: OECD Ülkeleri Üzerine Yatay Kesit Bağımlılığg Altında Yapısal Kırılmalı Panel Eşbütünleşme Analizi. Erciyes Üniversitesi İktisadi ve İdari Bilimler Fakültesi Dergisi, 48:145-174.

Kuznets, S. (1955). Economic Growth and Income Inequality. The American Economic Review, 45(1), 1-28.

Özdemir, D., Emsen, Ö.S., Hiç Gencer, A. ve Kılıç, C.H. (2011). Ekonomik Büyüme ve Gelir Dağılımı İlişkileri: Geçiş Ekonomileri Deneyimi. International Conference on Eurasian Economies 2011, Kirgizistan, 440-447.

Palacıoğlu, T. (2018). Döviz Kurlarında Son Gelişmeler. İstanbul Ticaret Odası (İTO) / İstanbul Düşünce Akademisi (İDA) 2018.

Peçe, M.A., Ceyhan, M.S. ve Akpolat, A. (2016). Türkiye'de Gelir Dağılımının Ekonomik Büyümeye Etkisi Üzerine Ekonometrik Bir Analiz. International Journal of Cultural and Social Studies (IntJCSS), 2(1): 135-148.

Perotti, R. (1993). Political Equilibrium, Income Distribution and Growth. The Review of Economic Studies, 60(4), 755-776.

Persson, T. ve Tabellini, G. (1994). Is Inequality Harmful for Growth: Theory and Evidence. American Economic Review, 84(3): 600-621.

Stanley, M. (2013). FX Pulse. New York: Morgan Stanley.

Şahin, D. (2018). Gelişmiş Ülkelerde Finansal Gelişme ve Gelir Eşitsizliği İlişkisi. Iğdır Üniversitesi Sosyal Bilimler Dergisi, 15:299-322. 
Tabosa, F.J.S., Castelar, P.U.C. ve Irffi, G. (2016). Brazil, 1981-2013: The Effects of Economic Growth and Income Inequality on Poverty. CEPAL Review, 120:153-170.

Topuz, S.G. ve Dağdemir, Ö. (2016). Ekonomik Büyüme ve Gelir Eşitsizliği İlişkisi: Kuznets Ters-U Hipotezi’nin Geçerliliği. Eskişehir Osmangazi Üniversitesi İİBF Dergisi, 11(3): 115- 130.

Topuz, S.G. ve Yıldırım, K. (2017). Gelir Eşitsizliğinin Ekonomik Büyüme Üzerindeki Etkisi. Anadolu Üniversitesi Sosyal Bilimler Dergisi, 17(3): 57-72.

Wahiba, N.F. ve El-Weriemmi, M. (2014). The Relationship Between Economic Growth and Income Inequality. International Journal of Economics and Financial Issues, 4(1): 135143.

Weil, D. (2016). Economic Growth. International Edition, Routledge.

Vo, D.H., Nguyen, T.C., Tran, N.P. ve Vo, A.T. (2019). What Factors Affect Income Inequality and Economic Growth in Middle-Income Countries. Journal of Risk and Financial Management, 12(40): 1-12.

Yanar, R. ve Şahbaz, A. (2013). Gelişmekte Olan Ülkelerde Küreselleşmenin Yoksulluk ve Gelir Eşitsizliği Üzerindeki Etkileri. Eskişehir Osmangazi Üniversitesi, İİBF Dergisi, $8(3): 55-74$. 